\title{
Physical Properties of Sol-Gel Lead Nickel Titanate Powder $\mathrm{Pb}\left(\mathrm{Ti}_{1-x} \mathrm{Ni}_{x}\right) \mathrm{O}_{3}$
}

\author{
Le Thi Mai Oanh ${ }^{1,2, *}$, Danh Bich Do ${ }^{1}$ and Nguyen Van Minh ${ }^{1,2}$ \\ ${ }^{1}$ Department of Physics, Hanoi National University of Education, 136 Xuan Thuy Road, Cau Giay District, Hanoi, 100000, Vietnam \\ ${ }^{2}$ Center for Nano Science and Technology, 136 Xuan Thuy Road, Cau Giay District, Hanoi, 100000, Vietnam
}

A series of sol-gel lead nickel titanate powder with composition of $\mathrm{PbTi}_{1-x} \mathrm{Ni}_{x} \mathrm{O}_{3}$, where $x=0.00,0.03,0.06,0.08,0.10$ and 0.12 , were studied using X-ray diffraction (XRD), scanning electron microscopy (SEM), Raman spectroscopy, and magnetization $(M-H)$ curves. XRD patterns show that $\mathrm{PbTi}_{1-x} \mathrm{Ni}_{x} \mathrm{O}_{3}$ materials well crystallize in tetragonal phase. The tetragonal distorted ratio $c / a$ of $\mathrm{PbTi}_{1-x} \mathrm{Ni}_{x} \mathrm{O}_{3}$ was found to decrease with the increase of $\mathrm{Ni}$ content and to increase with increasing calcining temperature. The mean size of $\mathrm{PbTi}_{1-x} \mathrm{Ni}_{x} \mathrm{O}_{3}$ crystal particles gradually decreased with increasing Ni content. Some Raman modes shifted to lower wavenumbers when Ni content increases, that is assigned to the variation of crystal structure due to the incorporation of $\mathrm{Ni}$ into $\mathrm{PbTiO}_{3}$ crystal. In addition, the results of room temperature magnetization measurements present an obvious improvement of ferromagnetism when Ni content increases in the range from 3 to 12 mol\%.

[doi:10.2320/matertrans.MA201508]

(Received January 21, 2015; Accepted May 12, 2015; Published June 26, 2015)

Keywords: tetragonal, ferromagnetism, sol-gel, ferroelectric

\section{Introduction}

Perovskite ferroelectric $\mathrm{PbTiO}_{3}$ is of fundamental scientific interest as well as varied technological application because of its extraordinary electromechanical properties in novel device development, such as nonvolatile memories, sensors, actuators, transducers, high-dielectric constant capacitors and tunable microwave circuits. ${ }^{1-3)}$ Recent efforts in introducing ferromagnetic order into this material by partially substituting B sites with transition-metal elements were performed to seek out a facility route to prepare multiferroics materials and develop new realistic devices based on the coupling between ferroelectric and ferromagnetic orders. Ren et al. ${ }^{4)}$ showed the transition of hysteresis loop from an anti-S-type $M-H$ curve for PT sample into typical S-type in $\mathrm{Fe}^{3+}$-doped $\mathrm{PbTiO}_{3}$ samples synthesized by hydrothermal process in which the author proposed that the mechanism leading to the ferromagnetism in the nanocrystals is F-center exchange (FCE) similarly to that in the Fe doped $\mathrm{SnO}_{2}$ nanocrystals. $\left.{ }^{5,6}\right)$ The largest ferromagnetic order was observed in $0.5 \% \mathrm{Fe}-$ doped $\mathrm{PbTiO}_{3}$ sample with $M_{\mathrm{S}} \sim 0.01 \mu_{\mathrm{B}} / \mathrm{Fe}$ and a coercive field of $\sim 100 \mathrm{Oe}$. Verma et al. ${ }^{7)}$ reported the largest ferromagnetic order in $1.2 \% \mathrm{Fe}^{3+}$-doped $\mathrm{PbTiO}_{3}$ sample synthesized by chemical route with $M_{\mathrm{S}} \sim 0.52 \mu_{\mathrm{B}} / \mathrm{Fe}$ and $H_{\mathrm{C}} \sim 125$ Oe. Palkar et al. ${ }^{8)}$ presented the conversion of ferroelectric $\mathrm{PbTiO}_{3}$ to magnetoelectric material by partially substituting $\mathrm{Ti}$ with $\mathrm{Fe}^{3+}$. The significant improvement of ferromagnetic property as well as magnetoelectric coupling at room temperature was also reported in ceramic $\mathrm{Mn}^{4+}$-doped $\mathrm{PbTiO}_{3}$ series by Kumar et al. ${ }^{9)}$ On the contrary, S. Stoupin et al. ${ }^{10)}$ argued that multiferroicity at room temperatures is unattainable in $\mathrm{PbTi}_{1-x} \mathrm{Mn}_{x} \mathrm{O}_{3}$. In addition, many theoretic calculations on doped and un-doped $\mathrm{PbTiO}_{3}$ were carried out to interpret the origin of the variation in ferroelectric as well as ferromagnetic orders in this single phase magnetoelectric material. ${ }^{11,12)}$ However, the efforts to find out the appropriate element doping were limited to only a few transition-metal ions such as $\mathrm{Fe}^{3+}, \mathrm{Mn}^{4+}$. The studies have not yet been

*Corresponding author, E-mail: Lemaioanh@gmail.com extended base on the substituting of many other elements into Ti sites.

Here, we report for the first time the influence of $\mathrm{Ni}^{2+}$ substitution on crystal structure, vibration and magnetic properties of $\mathrm{PbTiO}_{3}$ (PTO) nanocrystals synthesized by solgel process with Ni concentration ranging from 3 to $12 \mathrm{~mol} \%$ (Ni3, Ni6, Ni8, Ni10 and Ni12).

\section{Experimental Procedure}

Ni-doped $\mathrm{PbTiO}_{3}$ nanoparticles, $\mathrm{PbTi}_{1-x} \mathrm{Ni}_{x} \mathrm{O}_{3}$, were synthesized by sol-gel process using ethylene glycol (EG) as a surfactant. The $\mathrm{Ni}$ concentrations are designed as the molar ratio of $\mathrm{Ni} /\left(\mathrm{Ni}+\mathrm{Ti}\right.$ ) (in the form of $\mathrm{Ni}^{2+}$ ). Starting materials were titanium (IV) tetraisopropoxide $\mathrm{Ti}\left[\mathrm{OCH}\left(\mathrm{CH}_{3}\right)_{2}\right]_{4}$, lead nitrate $\mathrm{Pb}\left(\mathrm{NO}_{3}\right)_{2}$ and nickel nitrate $\mathrm{Ni}\left(\mathrm{NO}_{3}\right)_{2} \cdot 6 \mathrm{H}_{2} \mathrm{O}$. Titanium (IV) tetraisopropoxide was added into solution of acid citric and distilled water. This solution was stirred for $2 \mathrm{~h}$ at $80^{\circ} \mathrm{C}$ to achieve a colorless transparent solution. Lead nitrate and nickel nitrate were dissolved in separate cups of distilled water then poured slowly into above solution of Titanium. The obtained mixture solution was stirred for $1 \mathrm{~h}$ at $80^{\circ} \mathrm{C}$ to get a uniform emerald green sol containing the cations of $\mathrm{Pb}^{2+}, \mathrm{Ti}^{4+}$ and $\mathrm{Ni}^{2+}$. Ethylene glycol was then added into this sol as a surfactant. This sol was then vaporized gradually under low stirring and temperature of $90-100^{\circ} \mathrm{C}$ until a clear gel was obtained. Gel was dried at $180^{\circ} \mathrm{C}$ for $5 \mathrm{~h}$ then calcinated for $3 \mathrm{~h}$ at various temperatures from 500 to $900^{\circ} \mathrm{C}$ to crystallize the specimens.

The crystal structure and surface morphology of Ni doped $\mathrm{PbTiO}_{3}$ particles were characterized by XRD (SIEMENS D5000) with $\mathrm{Cu} \mathrm{K} \alpha$ radiation and scanning electron microscopes SEM (Hitachi S-4800), respectively. Raman scattering measurements were performed using a Jobin-Yvon T64000 spectrometer operated with $514.5 \mathrm{~nm}$ line of $\mathrm{Ar}$ ion laser. The magnetization vs. magnetic field was measured by a vibrating sample magnetometer (VSM-Micro Sence EZ-9). 


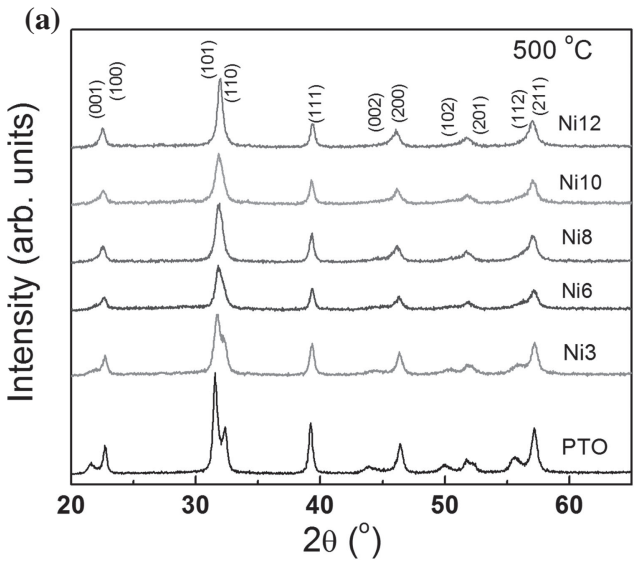

(b)

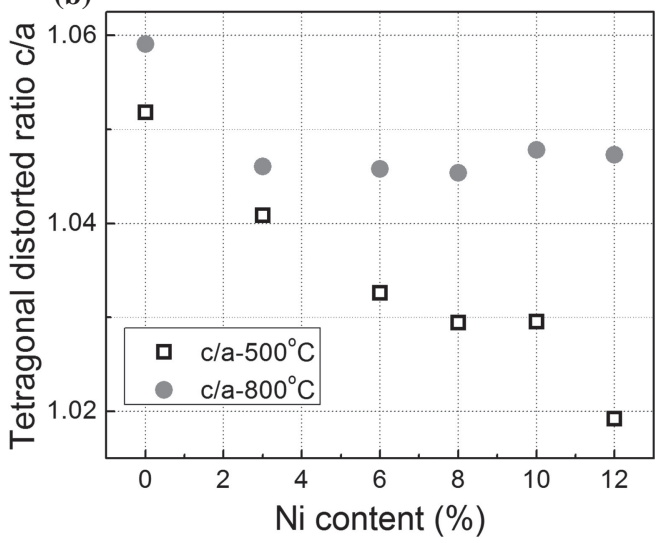

Fig. 1 (a) XRD patterns of $\mathrm{PbTi}_{1-x} \mathrm{Ni}_{x} \mathrm{O}_{3}$ powders heat treated at $500^{\circ} \mathrm{C}$ and (b) the dependence of tetragonal distorted ratio $c / a$ of

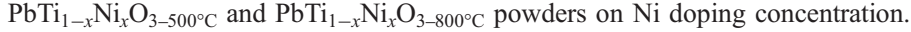
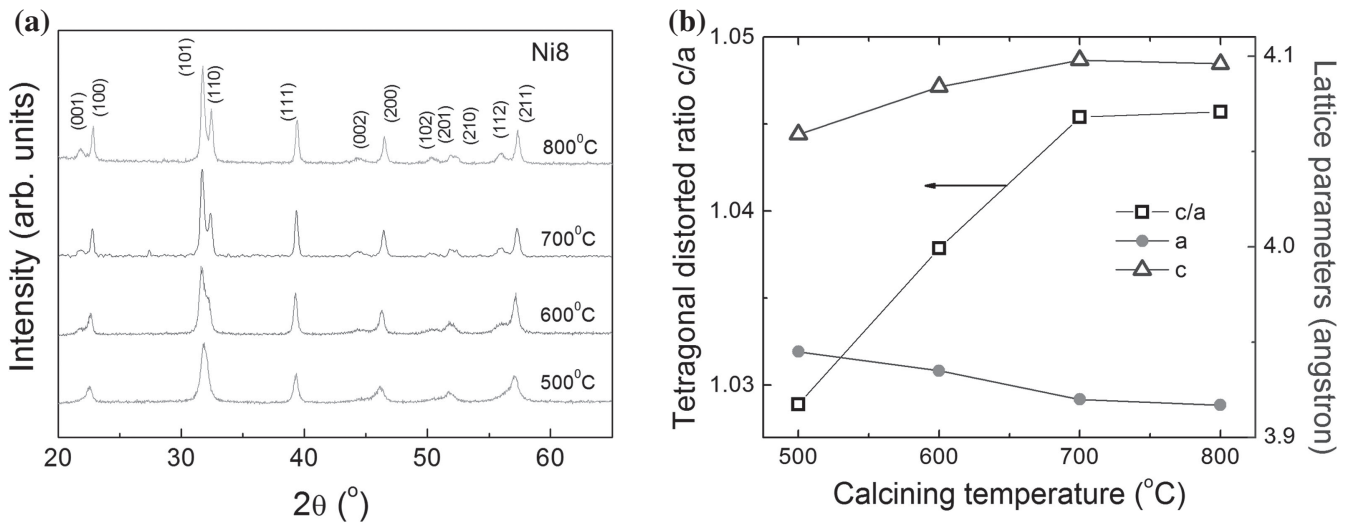

Fig. 2 (a) XRD patterns of Ni8 samples calcinated at different temperatures and (b) the influence of lattice parameters and tetragonal distorted ratio $c / a$ in Ni8 samples as a function of calcining temperatures.

\section{Results and Discussions}

The influence of the nickel content on $\mathrm{PbTiO}_{3}$ crystal structure can be observed in Fig. 1(a). This figure illustrates the XRD patterns for the $\mathrm{PbTi}_{1-x} \mathrm{Ni}_{x} \mathrm{O}_{3}$ powders heat treated at $500^{\circ} \mathrm{C}$ with $x$ ranging from 0 to $12 \mathrm{~mol} \%$. By indexing, XRD patterns of these samples are consistent with tetragonal structure phase of $\mathrm{PbTiO}_{3}$. Single phase and crystalline powders are obtained after this treatment up to $12 \mathrm{~mol} \%$ of Ni dopant. A gradual phase transformation from tetragonal to cubic with respect to the addition of $\mathrm{Ni}$ was evidenced by the left shift of XRD peaks such as (100), (110), (200), and (201) and the right shift of some other peaks such as (001), (101), (002), and (102). Consequently, tetragonal distorted ratio $c / a$ of $\mathrm{PbTi}_{1-x} \mathrm{Ni}_{x} \mathrm{O}_{3}$ samples decreases obviously from 1.051 for PTO to 1.020 for Ni12 (squares dotted line in Fig. 1(b)) in which lattice parameter $c$ sharply decreases from 4.11 to $4.01 \AA$ shile lattice parameter $a$ negligibly increases from 3.91 to 3.93 Á. This suppression in lattice distortion was also observed in many previous studies and was assigned to the replacing of dopant ions with different ion radius such as $\mathrm{Fe}^{3+4,7,8)}$ and $\mathrm{Mn}^{4+9)}$ into $\mathrm{Ti}^{4+}$ sites in the host $\mathrm{PbTiO}_{3}$ crystal lattice. It was claimed that the off-center displacement $D_{\mathrm{B}}$ of ion $\mathrm{Ti}^{4+}$ and electric polarization $P$ is proportional to tetragonality in ferroelectric $\mathrm{PbTiO}_{3}$-based solid solution, ${ }^{8,13}$ ) hence high $c / a$ ratio is required for high electric polarization perovskite material.

Figure 2(a) shows the XRD patterns of Ni8 samples which are heat treated at different temperatures. In contrast to Fig. 1(a), the gradual splitting of (101) and (110) doublet with increasing calcining temperature is the obvious evidence of the increase of tetragonality. The variation of lattice parameters $(a$ and $c$ ) as well as tetragonal distorted ratio $(c / a)$ as the function of calcining temperature is showed in Fig. 2(b). Tetragonality of sample increases remarkably in the early stage of temperature, from $c / a=1.029$ for $\mathrm{Ni}_{500^{\circ}} \mathrm{C}$ sample to $c / a=1.045$ for $\mathrm{Ni}_{700^{\circ} \mathrm{C}}$ sample. In the temperature range from 700 to $800^{\circ} \mathrm{C}, c / a$ ratio increases more slowly, reaching 1.046 for $\mathrm{Ni} 8800^{\circ} \mathrm{C}$ sample. In addition, XRD analysis of $\mathrm{PbTi}_{1-x} \mathrm{Ni}_{x} \mathrm{O}_{3}$ powders calcinated at $800^{\circ} \mathrm{C}$ for $3 \mathrm{~h}$ shows that tetragonality is well remained after substituting up to $12 \mathrm{~mol} \%$ of $\mathrm{Ni}$ dopant (the circle dotted line in Fig. 1(b)). $c / a$ ratio of $\mathrm{Ni} 12800^{\circ} \mathrm{C}$ sample is about of 1.044 , much higher than that of 1.019 of $\mathrm{Ni}_{500^{\circ} \mathrm{C}}$ sample. These results indicate that tetragonality $(c / a)$ and hence electric polarization can be easily controlled by calcining temperature.

FESEM images of PTO, Ni6 and Ni10 samples heat treated at $500^{\circ} \mathrm{C}$ are displayed in Fig. 3. It is estimated that the particle size of PTO sample is within the range from 40 to $60 \mathrm{~nm}$, averaging at about $50 \mathrm{~nm}$. The PTO powder exhibits 

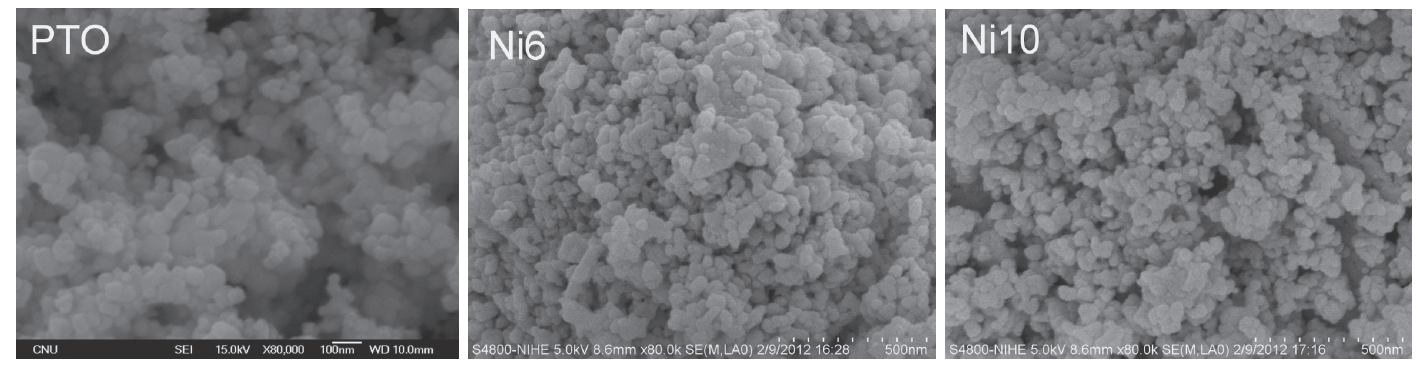

Fig. 3 FESEM images of $\mathrm{PTO}, \mathrm{Ni} 6$ and $\mathrm{Ni} 10$ samples heat treated at $500^{\circ} \mathrm{C}$.
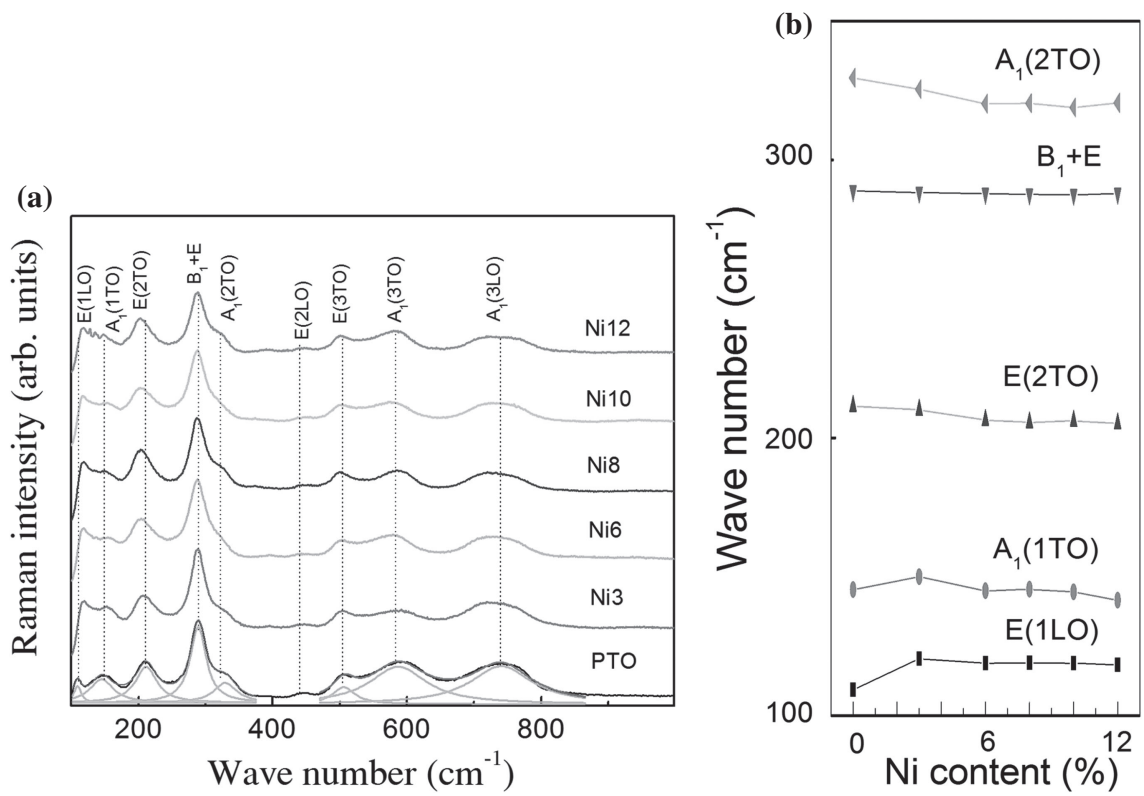

Fig. 4 (a) Raman spectra of $\mathrm{PbTi}_{1-x} \mathrm{Ni}_{x} \mathrm{O}_{3}$ powders calcinated at $500^{\circ} \mathrm{C}$ and (b) the dependence of Raman peak position on $\mathrm{Ni}$ content.

some rod-shape grains beside a relatively regular round shape. The average grain size of $\mathrm{PbTi}_{1-x} \mathrm{Ni}_{x} \mathrm{O}_{3}$ powders decreases gradually with $\mathrm{Ni}$ content which is estimated to be about $40 \mathrm{~nm}$ and $35 \mathrm{~nm}$ respectively for PNT6 and PNT10 sample. The suppression of particle growth process due to the replacement of $\mathrm{Ni}$ can be assigned to the difference in radii of $\mathrm{Ni}^{2+}$ and $\mathrm{Ti}^{4+}$.

The replacement of Ni into Ti sites in PTO crystal lattice has a huge influence on the vibration property of PTO powders, which is exhibited obviously in Raman spectra. Figure 4(a) shows Raman spectra of $\mathrm{PbTi}_{1-x} \mathrm{Ni}_{x} \mathrm{O}_{3}$ powders calcinated at $500^{\circ} \mathrm{C}$. In the region of $100 \div 900 \mathrm{~cm}^{-1}$, all samples exhibit 9 Raman peaks as assigned in Fig. 4(a). The variation of Raman peak position as a function of $\mathrm{Ni}$ content in Fig. 4(b) shows that $A_{1}$ peaks significantly shift to the lower wavenumber when $\mathrm{Ni}$ content increases. For example, $A_{1}(2 \mathrm{TO})$ and $A_{1}(3 \mathrm{TO})$ peaks respectively shift from 330 and $487 \mathrm{~cm}^{-1}$ to 321 and $478 \mathrm{~cm}^{-1}$ when $\mathrm{Ni}$ concentration increases from 0 to $12 \mathrm{~mol} \%$. Meanwhile, $E$ and $B_{1}$ peaks almost do not change their position with the increase of $\mathrm{Ni}$ content up to $12 \mathrm{~mol} \%$. This can be explained from the sharp decrease of lattice parameters $c$ with increasing $\mathrm{Ni}$ content

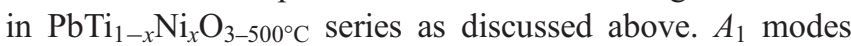
consist of the displacements of Ti ion along the $c$ axis relative to $\mathrm{O}$ ions and $\mathrm{Pb}$ ions while $E$ modes consist the displacements of Ti ion along $a$ or $b$ axis and $B_{1}$ mode consists the displacement of $\mathrm{O}$ ions in $a b$ plane along $c$ axis. ${ }^{14)}$ The significant decrease of $c$ parameter only strong affects to the vibration of Ti ion along $c$ axis hence resulting the left-shift of $A_{1}$ mode which is similar to the left-shift occurred under tetragonal-cubic transition with increasing temperature. ${ }^{14)}$ In addition, the decrease of frequency of $\mathrm{Ti}^{4+}$-related Raman modes also can be originated from heavier atom weight of $\mathrm{Ni}^{2+}$ cations with respect to $\mathrm{Ti}^{4+}$ cations, implying the replacement of $\mathrm{Ni}^{2+}$ ions into $\mathrm{Ti}^{4+}$ sites.

Figure 5 displays $M-H$ curves of high tetragonality $\mathrm{PbTi}_{1-x} \mathrm{Ni}_{x} \mathrm{O}_{3}$ samples calcined at $900^{\circ} \mathrm{C}$. $M-H$ curve of PTO sample in the insert figure shows intrinsic diamagnetism of $\mathrm{PbTiO}_{3}$ material which comes from $3 \mathrm{~d}^{\circ}$ electron configuration of $\mathrm{Ti}^{4+}$ ion. ${ }^{4)}$ The existence of a weak ferromagnetic order in pure phase $\mathrm{PbTiO}_{3}$ can be assigned to the oxygen vacancy which causes a very small saturation magnetization about of $0.0006 \mathrm{emu} / \mathrm{g} .{ }^{11,12)}$ All $\mathrm{PbTi}_{1-x} \mathrm{Ni}_{x} \mathrm{O}_{3}$ samples exhibit the S-type $M-H$ curves of ferromagnetism with the gradually increase of both coercive force $H_{\mathrm{C}}$ and saturation magnetization $M_{\mathrm{S}}$ with increasing $\mathrm{Ni}$ content. For Ni12 sample, the values of saturation magnetization $M_{\mathrm{S}}$ and coercive field $H_{\mathrm{C}}$ reach to $0.0056 \mathrm{emu} / \mathrm{g}$ and $705 \mathrm{Oe}$, respectively. Bound magnetic polaron model, first proposed by Torrance, ${ }^{15)}$ can be employed to explain the ferromagnetism in $\mathrm{PbTi}_{1-x} \mathrm{Ni}_{x} \mathrm{O}_{3}$ materials. In such model, an electron associated with an oxygen vacancy will be confined in a 


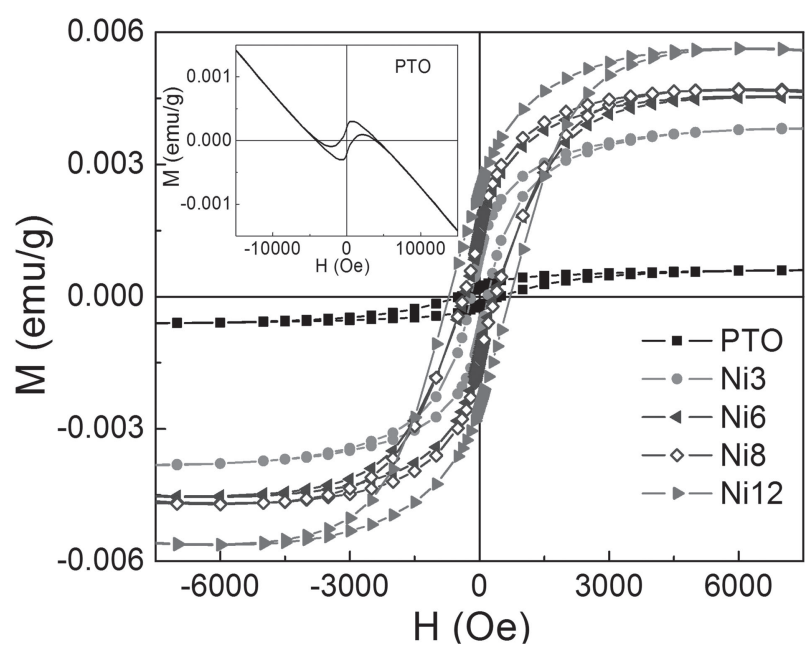

Fig. 5 The $M-H$ curve of PTO, Ni3, Ni6, Ni8 and Ni12 powders calcined at $900^{\circ} \mathrm{C}$ (the insert figure displays the intrinsic diamagnetism nature of pure $\mathrm{PbTiO}_{3}$ material).

hydrogenic orbital which is called donor electron. These electrons tend to form bound magnetic polarons, coupling the $3 \mathrm{~d}$ moments of the ions within their orbits. ${ }^{16)}$ The effective coupling between two $\mathrm{Ni}^{2+}$ magnetic ions in the same hydrogenic orbital is ferromagnetic. As the density of impurity ions increases, the number of $\mathrm{Ni}^{2+}$ ions in the same electron orbital increases leading to the increases of total magnetic moment. Otherwise, the electric neutralization condition also leads to the increase of oxygen vacancies density with increasing $\mathrm{Ni}^{2+}$ content which results to the overlapping between the different hydrogenic orbitals. ${ }^{16)}$ Thus, total magnetization will still increases until $\mathrm{Ni}^{2+}$ content is large enough to make the appearance of antiferromagnetic super-exchange interactions, which reduce the average magnetic moment per doping ion due to the antiferromagnetic order $\uparrow \downarrow \uparrow$.

\section{Conclusions}

In summary, the influences of $\mathrm{Ni}^{2+}$ substitution on crystal structure, vibration and magnetic properties were observed in $\mathrm{PbTi}_{1-x} \mathrm{Ni}_{x} \mathrm{O}$ nanocrystals prepared by sol-gel method with $\mathrm{Ni}$ concentration ranging from 0 to $12 \mathrm{~mol} \%$. Tetragonal distorted ratio $c / a$ decreased with increasing $\mathrm{Ni}$ content, demonstrating the substitution of $\mathrm{Ni}$ into $\mathrm{PbTiO}_{3}$ crystal lattice, and increased with increasing calcining temperature, benefiting for ferroelectric polarization. The substitution of $\mathrm{Ni}$ into $\mathrm{PbTiO}_{3}$ crystal lattice was also proved by the left-shift of Raman peaks related to Ti vibration along $c$ axis. Roomtemperature ferromagnetism of $\mathrm{PbTi}_{1-x} \mathrm{Ni}_{x} \mathrm{O}_{3}$ nanocrystals calcined at $900^{\circ} \mathrm{C}$ improved in the range of $\mathrm{Ni}$ doping concentration from 0 to $12 \mathrm{~mol} \%$. The observation of room temperature ferromagnetism in high tetragonality $\mathrm{PbTi}_{1-x^{-}}$ $\mathrm{Ni}_{x} \mathrm{O}$ series may provide an approach to widely explore more single-phase multiferroics.

\section{Acknowledgement}

This research is funded by Vietnam National Foundation for Science and Technology Development (NAFOSTED) under grant number 103.02-2014.21.

\section{REFERENCES}

1) N. Setter, D. Damjanovic, L. Eng, G. Fox, S. Gevorgian, S. Hong, A. Kingon, H. Kohlstedt, N. Y. Park, G. B. Stephenson, I. Stolitchnov, A. K. Taganstev, D. V. Taylor, T. Yamada and S. Streiffer: J. Appl. Phys. 100 (2006) 051606.

2) V. G. Bhide, K. G. Deshmukh and M. S. Hegde: Physica 28 (1962) 871.

3) M. Okuyama and Y. Hamakawa: Int. J. Eng. Sci. 29 (1991) 391.

4) Z. Ren, G. Xu, X. Wei, Y. Liu, X. Hou, P. Du, W. Weng, G. Shen and G. Han: Appl. Phys. Lett. 91 (2007) 063106.

5) A. Punnoose, J. Hays, A. Thurber, M. H. Engelhard, R. K. Kukkadapu, C. Wang, V. Shutthanandan and S. Thevuthasan: Phys. Rev. B 72 (2005) 054402.

6) J. M. D. Coey, A. P. Douvalis, B. Fitzgerald and M. Venkatesan: Appl. Phys. Lett. 84 (2004) 1332.

7) K. C. Verma, R. K. Kotnala and N. S. Negi: Appl. Phys. Lett. 92 (2008) 152902.

8) V. R. Palkar and S. K. Malik: Sol. State Commun. 134 (2005) 783.

9) M. Kumar and K. L. Yadav: J. Phys. Condens. Matter 19 (2007) 242202.

10) S. Stoupin, S. Chattopadhyay, T. Bolin and C. U. Segre: Sol. State Commun. 144 (2007) 46.

11) T. Shimada, Y. Uratani and T. Kitamura: Acta Mater. 60 (2012) 6322.

12) T. Shimada, Y. Uratani and T. Kitamura: Appl. Phys. Lett. 100 (2012) 162901.

13) T. Qi, I. Grinberg and A. M. Rappe: Phys. Rev. B 82 (2010) 134113.

14) J. D. Freire and R. S. Katiyar: Phys. Rev. B 37 (1988) 2074.

15) J. B. Torrance, M. W. Shafer and T. H. McGuire: Phys. Rev. Lett. 29 (1972) 1168.

16) J. M. D. Coey, M. Venkatesan and C. B. Fitzgerald: Nature Mater. 4 (2005) 173. 